\title{
Bilateral spontaneous pneumothorax in sarcoidosis
}

\author{
RICHARD J. M. ROSS \\ M.B., M.R.C.P.
}

\author{
D. W. EMPEY \\ M.B., M.R.C.P.
}

The London Hospital, Whitechapel, London E1 IBB

\begin{abstract}
Summary
Sarcoidosis, early in the disease, is rarely complicated by pneumothoraces. We report a case of simultaneous bilateral spontaneous pneumothoraces affecting a young man with early sarcoidosis.

KEY WORDS: pneumothorax, sarcoidosis.

\section{Introduction}

Pleural involvement is a rare complication of sarcoidosis. It may appear as pleural effusions, pleural thickening, pneumothorax, or as an incidental finding at thoracotomy. Pneumothorax is rare in the early stages of sarcoidosis and has not previously been described as occurring on both sides simultaneously.
\end{abstract}

\section{Case report}

A symptomless 42-year-old West Indian male first presented in 1975 when hypertension had been noted at a routine medical examination. Blood pressure was $170 / 110 \mathrm{~mm} \mathrm{Hg}$ but routine clinical examination and investigations including the chest X-ray, were normal. His hypertension was controlled on a diuretic and by beta-blockade.

In July 1979 he complained of breathlessness on exercise. Blood pressure was $120 / 80 \mathrm{mmHg}$ and apart from crepitations at both bases there were no abnormal physical signs. Chest $\mathrm{X}$-ray showed a moderately large heart and bilateral hilar lymphadenopathy with a reticulo-nodular infiltrate affecting mainly the mid and lower zones. Pulmonary function showed a mild restriction defect with some reduction in diffusing capacity. Biopsy of a Kveim test showed typical non-caseating granulomata and a diagnosis of sarcoidosis was made. He was started on prednisolone $20 \mathrm{mg}$ daily and one month later was symptomatically improved, although his chest X-ray had not changed. Steroids were gradually reduced and he was maintained on $7.5 \mathrm{mg}$ daily.

In July 1980 he developed scaly patches on his scalp and small nodules on his lips and legs. Biopsy of a lip nodule showed typical non-caseating granu- lomata. His steroids were continued at a dose of $7.5^{\circ}$ $\mathrm{mg}$ daily and, in November 1980, some increase iro the infiltrate was noted. In January 1981 he was. breathless on exercise and a left-sided pneumothoraxo was seen. His breathlessness increased over theo following months and, in August, it was noted that heo had a palpable liver and spleen. His chest X-ray now $\vec{\circ}$ showed a small right-sided pneumothorax and persis-o tence of the left-sided pneumothorax (Fig. 1). Liver biopsy showed non-caseating granulomata, typical of sarcoidosis, and his prednisolone was increased to $60 \mathrm{D}$ $\mathrm{mg}$ daily. This was gradually reduced to $30 \mathrm{mg}$ daily? and both his pneumothoraces have now resolved and his symptoms have improved.

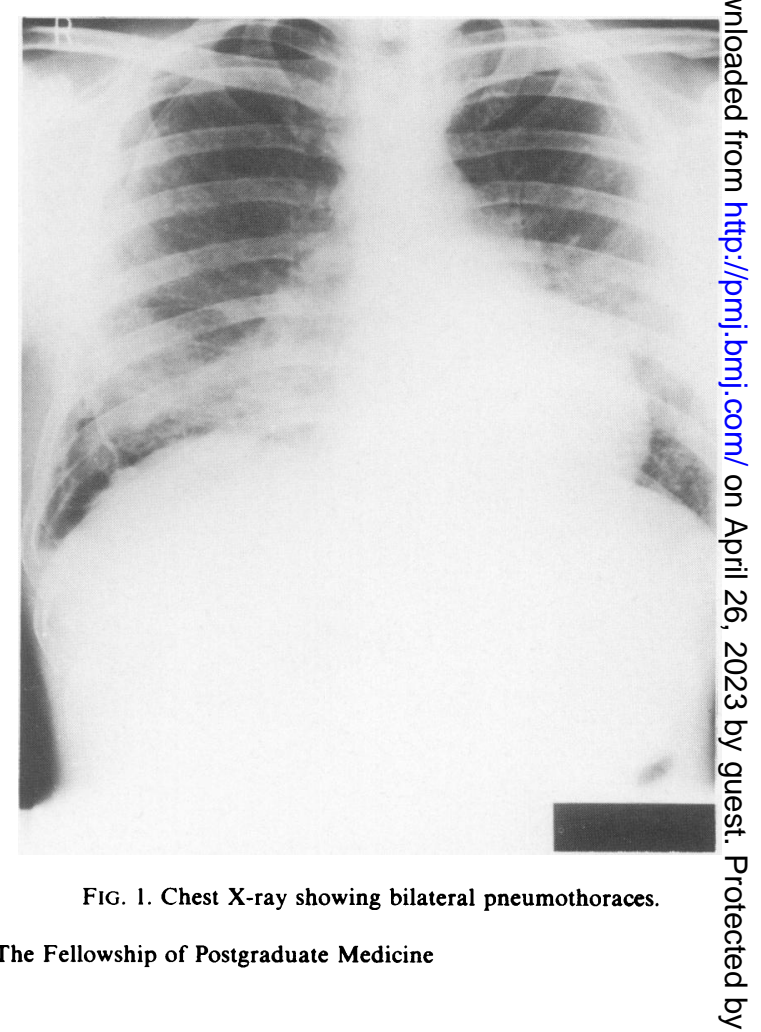




\section{Discussion}

Pneumothorax as a complication of late fibrotic sarcoidosis and the associated bullous changes in the lungs are well recognized. Very few cases have been reported, however, as a feature of early sarcoidosis.

Riley (1950) was the first to report pneumothorax as a complication of sarcoidosis and described 2 cases out of a series of 52 patients. In one of these, the pneumothoraces were recurrent and there were obvious emphysematous cystic changes in the lung. Riley suggested that the cause in such patients might be the rupture of a subpleural cyst or possibly the necrosis of a subpleural granuloma.

Sharma (1977) found 5 patients who developed pneumothoraces in a series of 180 patients, with histologically proven sarcoidosis. In 2 who had thoracotomy, multiple non-caseating granulomata involving the pleura were seen. Scadding (1967) also reported 5 cases of sarcoid complicated by pneumothorax. Three of these were young men in whom he felt the condition was coincidental, but the other 2 were negro women of middle age with late fibrotic sarcoid and bullous emphysematous changes evident on the chest X-ray. Both required repeated drainage for recurrent pneumothoraces.

Pneumothorax as a complication of late stage fibrotic sarcoid, with associated bullous changes, is not unexpected. Pneumothorax as the cause of breathlessness in the earlier stages of sarcoid is very unusual and our patient is the first one in whom simultaneous bilateral pneumothoraces have been reported. Pneumothorax should be considered when patients with active sarcoidosis become breathless, rather than attributing the symptoms to pulmonary infiltration alone.

\section{References}

RILEY, E.A. (1950) Boeck's sarcoid: A review based upon a clinical study of fifty-two cases. American Review of Respiratory Diseases, 62, 231.

SCADDING, J.G. (1967) Sarcoidosis, 1st edn. Eyre \& Spottiswoode, London.

SHARMA, O.P. (1977) Sarcoidosis: unusual pulmonary manifestations. Postgraduate Medicine, 61, 67.

(Accepted 4 June 1982) 